\title{
ARTICULAÇÕES ENTRE RELIGIÃO E CULTURA POP EM CINCO PORTAIS VOLTADOS PARA O PÚBLICO "NERD" E "GEEK" RELIGIOSO'
}

\section{ARTICULATIONS BETWEEN RELIGION AND POP CULTURE IN FIVE 'NERD’ AND 'GEEK’ DENOMINATIONAL WEBSITES}

Luis Mauro Sá Martino*

\begin{abstract}
RESUMO:
À primeira vista, a religião e cultura pop pertencem a espaços distantes da experiência humana, no entanto, nas últimas décadas, a religião tem se valido da mídia e do entretenimento para manter sua mensagem próxima de públicos mais amplos. Este artigo delineia a relação entre religião e cultura pop em cinco sites que unem mensagens religiosas e entretenimento, como filmes de ação, quadrinhos e séries de TV. A partir da análise da mensagem dos portais, foi possível encontrar três principais formas de articulação da cultura pop com o conteúdo denominacional: (1) o vínculo entre religião e entretenimento como definidor de uma identidade; (2) enquadrando personagens da cultura pop em um contexto religioso e (3) o emprego do entretenimento como ponto de partida para discutir questões morais e religiosas. Esses pontos são analisados a partir dos estudos de midiatização da religião.
\end{abstract}

\section{PALAVRAS-CHAVE:}

Midiatização da religião, entretenimento, cultura pop.

\section{ABSTRACT:}

At first, religion and pop culture belong to two distant realms of human experience. However, in recent decades, religion has been drawing on its secular media and entertainment counterparts to convey their message to broader audiences. This paper outlines the relationship between religion and popular culture in five websites that combine religious messages and entertainment such as action movies, comics, and TV series. The analysis of the texts, pictures, and products published in the website revealed three main ways through which popular culture articulates with denominational content:

* Professor do Programa de Pós-Graduação em Comunicação da Faculdade Cásper Líbero. Doutor em Ciências Sociais pela PUC-SP. Email: Imsamartino@gmail.com 
(1) the religion-entertainment link as an identity defining site; (2) the framing of pop characters in a religious context; and (3) popular culture as a trigger to discuss moral and religious issues. These findings are discusses based on studies on the mediatization of religion.

\section{KEYWORDS:}

Mediatization of religion, entertainment, pop culture.

\section{INTRODUÇÃO}

As relações entre mídia e religião vêm sendo um objeto privilegiado de análise há pelo menos três décadas, com um número crescente de artigos, livros e eventos dedicados ao estudo desse tema. Vista ora dentro de uma perspectiva mais ampla de midiatização da sociedade, como em Hjarvard (2008) ou Fingenbaum (2006), ora em sua especificidade, como Gomes (2004) ou Martino (2016a; 2016b), essa perspectiva de análise procura compreender as dimensões das práticas e vivências religiosas em uma sociedade marcada pela presença das mídias em suas várias formas.

Uma das dimensões dessa ligação é a aproximação entre denominações e práticas religiosas e a chamada “cultura pop”, uma intersecção na qual é possível observar um trânsito de referências entre esses dois universos. Se, em algum momento, religião e cultura pop foram dimensões estanques da experiência humana, é possível observar uma transformação nesse panorama com uma progressiva articulação farto em tensões e questionamentos entre esses dois elementos, como indicam Clark (2002; 2007), Romanowski (2006) ou McDanell (2012).

Na produção acadêmica, nota-se, com Hjarvard (2008), Borelli (2012) ou Martino (2016a), certo distanciamento da perspectiva de compreender as relações entre "mídia" e "religião", vistas como práticas sociais separadas, em prol de uma perspectiva que leve em consideração sua imersão em um ambiente midiático caracterizado pela conexão constante e circulação de sentidos se articula com as vivências religiosas cotidianas, a midiatização da religião.

Ao mesmo tempo em que as formas tradicionais de institucionalização religiosa, sobretudo no formato tradicional da "assembleia" ou "igreja”, na tipologia clássica de Weber (1991), se mantém na atualidade, nota-se também a emergência de novas formas de vivência religiosa ligadas à experiência de conexão via mídias digitais entre o individual 
e o coletivo, com transformações tanto em termo de forma quanto de conteúdo, como aponta Miklos (2012), para não mencionar as mudanças nas práticas religiosas.

A intersecção entre mídia e religião parece, nesse aspecto, operar não apenas no campo institucional, mas também na produção e circulação de sentidos, referências e narrativas, entre as quais é possível destacar as ligações com a chamada "cultura pop”. A utilização dos códigos do ambiente midiático por denominações religiosas aponta, como indicado por autoras e autores, uma ligação não apenas em termos de forma, mas também de conteúdo - cf. Clark (2001), Buddenbaum (2002), Stout e Buddenbaum (2002), Marchessault (2011) ou Cunha (2013). Em algumas dimensões, o processo de midiatização da religião apresenta um movimento de aproximação entre doutrinas e práticas religiosas de um lado e o entretenimento de outro.

A relação entre religião e cultura pop, à primeira vista, talvez não seja intuitiva e apresente-se mesmo como paradoxal sob certos aspectos. Em geral, entende-se por cultura pop um tipo de prática cultural voltada sobretudo para o entretenimento, ligada ao tempo livre e à diversão, enquanto a religião trataria de assuntos sérios, relacionados às práticas sociais e particulares, pautadas na fé de pessoas e grupos. Ao caráter de entretenimento da cultura pop poderia ser oposta a seriedade da religião enquanto forma da experiência humana. No entanto, as aproximações entre essas duas instâncias vêm sendo não apenas constantes, mas progressivamente mais entrelaçadas nas últimas décadas, conforme o ambiente da mídia se expande na sociedade - e em suas relações econômicas e políticas.

Este artigo delineia aspectos iniciais de uma pesquisa sobre relação entre religião e cultura pop tal como são mostradas em cinco sites sobre cultura gospel e pop, voltados para a intersecção entre mensagens religiosas e entretenimento, como filmes de ação, quadrinhos e séries de TV. O objetivo aqui é, a partir da análise dos textos, fotos e produtos à venda nos sites, observar as formas de intersecção entre cultura pop e conteúdos denominacionais.

Foram analisados cinco portais identificados, em mecanismos de busca, a partir das entradas “cristão”, “gospel”, “católicos” e “evangélicos” de um lado, e “entretenimento", “nerd”, “geek" e "cultura pop” de outro. Uma busca inicial colocou lado a lado portais dedicados ao tema, páginas de vendas, menções esparsas em textos produzidos por instituições religiosas ou referências de passagem em artigos sobre outros assuntos. 
A partir desse resultado inicial, refinou-se a busca utilizando-se, como critério, páginas com temáticas religiosas que fizessem referência direta, em seus títulos ou descrições, a uma das palavras-chave utilizadas na busca, chegando-se a cinco portais: Parábola Geek, O Cristão Nerd, Bando de Quadrados, Loja Nerd Cristão e Loja KOK. Como os nomes indicam, as três primeiras são portais de notícias, textos e informações sobre entretenimento e religião, com diferenças em seu tratamento, contendo textos, vídeos e, no caso do Bando de Quadrados e de O Cristão Nerd, também podcasts; enquanto isso, as duas últimas são páginas de vendas de produtos, como canecas e camisetas, com temática religiosa e da cultura pop.

Como definição de limites para este artigo, optou-se pela análise da narrativa pop religiosa construída a partir dos textos e imagens nas páginas, deixando de lado vídeos e podcasts - um estudo completo tenderia a extrapolar os limites deste artigo. Procurouse, nos textos e imagens, observar os momentos nos quais cultura pop e religião se entrelaçavam diretamente, buscando, quando necessário, concentrar a análise nas postagens mais recentes conforme o caso. Foram salientados os pontos comuns dessa intersecção entre religião e cultura pop presentes nos cinco sites: aspectos específicos foram destacados apenas quando pertinentes a esse tema. Tomados em seu conjunto, eles apresentam um panorama das características de um fenômeno mais amplo, a midiatização da religião; ao mesmo tempo, em termos do material empírico, considerou-se mais frutífero trabalhar a partir de um número mais de sites do que concentrar a análise em um - razão pela qual foi escolhida a construção do objeto.

A análise mostrou três formas principais de articulação entre mídia e religião em torno das quais o texto se organiza: (1) a autoidentificação das páginas em termos de sua dupla vinculação como fiel de uma denominação e fã da cultura pop; (2) as adaptações religiosas do entretenimento nos produtos à venda; e (3) a cultura pop como ponto de partida para a discussão de temas. Como nota, vale recordar que o objetivo aqui é discutir aspectos relacionados à mídia, não aspectos doutrinários ou relacionados às práticas desta ou daquela denominação religiosa.

\section{A DEFINIÇÃO DE UMA IDENTIDADE ENTRE O FÃ E O FIEL}

Um aspecto inicial a considerar, como indício do tema deste artigo, é o nome dos portais de informação e/ou produtos consultados. Entendendo todo nome como tentativa de delimitação conceitual de um recorte da realidade, é possível começar a análise 
a partir das denominações utilizadas pelas páginas para definirem a si mesmas. Isso pode auxiliar a situar tanto os limites entre espaços culturais quanto preparar o terreno para a observação de suas intersecções.

Nota-se, nos sites Parabolas Geek, O Cristão Geek e Nerd Cristão a referência direta há “geek” e “nerd”, ao contrário dos outros, Loja KOK e Bando de Quadrados, embora este último, na página inicial, tenha como título de um dos canais "Palavra Nérdica", na qual o termo "nerd” aparece.

Um delineamento inicial desses nomes sugere uma proximidade com o mundo da cultura pop, sobretudo no caso de "nerd", ou, pendendo um pouco mais para questões tecnológicas, em "geek", embora essas fronteiras sejam mais delimitadas em termos de conceitualização do fenômeno do que na realidade, como mostram os trabalhos sobre entretenimento e cultura pop de Fiske (1998), Dyer (1998), McRobbie (2003), Trigo (2003), Soares (2014) ou Adriana Amaral (2016). Por sua vez, as distinções entre "nerd" e "geek" são também fluidas, assim como suas relações com a cultura pop, algo indicado por Matos (2011, 2012), Bicca et al. (2013) ou Santos et al. (2015). Se a complexidade das intersecções entre práticas culturais desafia qualquer proposta de indicar contornos mais nítidos, ao mesmo tempo, a reivindicação desses limites pode ser também uma forma de “distinção” cultural, no sentido proposto por Bourdieu (2011). Vale, por isso mesmo, lançar um olhar às autodefinições dos portais.

O Parábolas Geek apresenta uma definição a partir dos formatos, referindo-se a "universo geek" como o espaço de "HQs, Filmes, Seriados, Literatura, entre outras formas de mídia”. O termo “geek" não é referido em termos de utilização ou conhecimento da tecnologia, mas a partir da vinculação com produtos indicados, sintomaticamente, como "formas de mídia” (PARABOLAS GEEK, 2020) - não no sentido do "meio de comunicação", mas como referência aos discursos produzidos e divulgado por empresas de comunicação. As definições de O Cristão Geek, da Loja KOK e do Bando de Quadrados não são diretas, mas podem ser inferidas a partir dos temas e produtos em destaque, referindo-se sempre aos conteúdos da mídia.

As práticas culturais, recorda Bourdieu (2011), podem ser compreendidas como um complexo sistema de classificações, hierarquizações e luta pela definição de espaços simbólicos vistos como dotados de maior ou menor prestígio. Historicamente, a cultura pop, ligada às formas de produção e consumo de mídia, tem sido um alvo privilegiado 
de crítica, o quer parecia exclui-la, junto com o entretenimento, de espaços voltados para discursos ou práticas "sérias". No contexto religioso, argumentam Cosgel e Lanse (2004), "normas de consumo facilitam a comunicação diminuindo o conhecimento necessário para codificar e decodificar mensagens, e restringindo as escolhas possíveis para um conjunto menor" (p. 344).

No campo das práticas culturais, a cultura pop esteve durante um bom tempo associada aos níveis inferiorizados, sobretudo quando contrastada com formas, histórica e socialmente consagradas de cultura. No entanto, autoras e autores como Street $(1986 ; 2001)$, Van Zoonen (2005), Brabazon (2008), Panke (2010) e Martino (2019) indicam a possibilidade de reavaliar o lugar da cultura pop e do entretenimento no âmbito das práticas culturais e considerar seu potencial na discussão de questões políticas, econômicas e sociais, em particular aquelas ligadas à identidade de indivíduos e comunidades. Como salienta Dyer (1998), longe de ser “apenas entretenimento”, a cultura pop se apresenta como um espaço de apresentação, representação e debate de temas relevantes.

Embora a maior parte dessas autoras e autores indiquem a relevância da cultura pop no âmbito das discussões políticas, é possível ampliar essa discussão no âmbito de sua intersecção com algumas formas de religiosidades, como Souza (2004), Souza (2005) ou Martino (2016b).

Os portais são pautados em termos das práticas culturais de seus criadores ou responsáveis. Eles se apresentam não apenas como apreciadores ou consumidores, mas como agentes interessados na reelaboração criativa das mensagens da mídia, relacionando-as com o universo religioso. As descrições das criadoras e criadores, em seções intituladas “Quem somos" ou "Sobre nós”, complementam as definições indicadas nos nomes de cada portal.

Nessas páginas ou seções, é possível observar as referências utilizadas como indicadores das práticas culturais associadas aos universos "geek" e "nerd", a começar pelo uso dessas palavras. Vale, no entanto, levar em conta a advertência sobre os limites deste tipo de análise feita por Ramos e Patriota (2018): “a autoidentificação dos seus membros pode ser problemática pela fluidez e intangibilidade das experiências nelas vividas e narrativizadas" (p. 122). Estas referências são, portanto, mais indicações do que tentativas de circunscrever práticas a um conceito. 
Nesse aspecto, vale retomar as definições oferecidas pelos portais em suas autoidentificações:

(1) Geek/nerd: palavras recorrentes na autodefinição dos idealizadores, criadores e participantes dos portais. Essas expressões não são desenvolvidas ou explicadas nos sites, ausência que pode ser compreendida como indicação do público esperado, que, por pertencerem a esses grupos, não necessitam de explicação. O vínculo com uma prática cultural parece ser suficiente para o reconhecimento mútuo no "contrato de leitura", como define Fausto Neto (2006), entre os portais e seu público: uma nerd ou um geek não precisa encontrar uma explicação do que é isso em uma loja voltada para eles. A necessidade de explicação do código costuma indicar a ausência de vínculo com uma prática cultural ou consumo estético. Isso não significa a inexistência de definições ou indicações do que a palavra significa: elas decorrem do processo de consumo indicado, o que leva ao próximo item.

(2) História em quadrinhos: as referências são em termos da disputa, ecoada em alguns círculos de fãs, entre as empresas Marvel e DC, com diversos posicionamentos sobre cada uma delas, incluindo o questionamento desse tipo de concorrência no âmbito dos consumidores de quadrinhos. Não há, nas identificações, menção aos filmes derivados das histórias em quadrinhos, mas ambos são referidos, às vezes, como "franquia", independentemente da mídia. Desse universo, Batman e Liga da Justiça são citados nominalmente.

(3) Mangás e animes: o que Lyuten (2006) denomina "cultura pop japonesa" está presente nas autodefinições do que significa ser "nerd" ou "geek" nos portais estudados, com referências diretas a produções como Cavaleiros do Zodíaco, Dragon Ball e Pokémon. A valorização desse tipo de produto, bem como sua inclusão dentro dos universos da cultura pop, parece ser relativamente tardia, a julgar pelos trabalhos de Lyuten.

(4) RPG/games: como destacam Feitoza e Santaella (2008), a emergência do game como parte da cultura da mídia também é recente, e seu vínculo com as práticas do pop parecem derivar, sobretudo, do trânsito de narrativas entre diversas plataformas. São mencionados, nas autoidentificações, "RPGs" e "games" em termos gerais (como em "E-sports" e "Medievais"), com duas individualizações, uma referente a um produto, Super Nintendo, a outra ao jogo Legends of Zelda.

Além disso, como indicado, há também menções a "filmes" e "seriados", mas sem indicar títulos específicos.

É possível, a partir daí, delimitar o universo "geek" e “nerd” dos sites a partir das práticas culturais indicadas nas descrições dos portais e na apresentação dos participantes. Os elementos de destaque, HQs, filmes e seriados; mangás e animes, RPG e games oferecem uma visão do campo coberto pelas definições em termos de sua vinculação com o universo das produções e práticas midiáticas. As definições são feitas a partir de narrativas de consumo, não necessariamente de uma conceituação - o que talvez não fosse o caso. 
Uma segunda perspectiva diz respeito à identificação do vínculo religioso. Os quatro portais analisados se denominam “cristãos”. Menções a denominações religiosas, sempre breves, ficam restritas às identificações individuais. As ligações evidenciadas não são com agentes específicos do campo religioso, mas com o chamado "protestantismo neopentecostal”, segundo Mariano (1999).

Os vínculos de comunidade e identidade, nos portais, são construídos ao redor da intersecção entre religião e cultura pop, sem destacar vínculos institucionais particulares, mas reivindicando seu posicionamento no campo religioso e como fiéis em uma sociedade secular. A visibilidade desses dois polos é semelhante: referências à Bíblia caminham lado a lado com menções a personagens de filmes e histórias em quadrinhos, e raramente um desses itens aparece de maneira isolada. Essa intersecção entre campos também aparece na descrição das páginas.

O Parábola Geek indica que “o objetivo é alcançar jovens e adolescentes com uma linguagem inteligível dentro do universo deles" (PARABOLAS GEEK, 2020), pautada em uma passagem da Bíblia. A loja Nerd Cristão segue uma linha semelhante: "Com o foco de levar a palavra de Deus com um toque Nerd, usando a criatividade para oferecer um produto diferenciado". Na descrição do portal Bando de Quadrados, o caminho parece ser uma interpretação religiosa da cultura pop: segundo a página, seus idealizadores "viram uma oportunidade de falar e noticiar sobre a cultura pop através de outra nova perspectiva".

Essa articulação parece ser uma das características mais evidentes do processo de midiatização no sentido proposto em outros momentos - cf. Martino (2016a; 2016b; 2019) como articulação entre o ambiente das mídias, de um lado, e as práticas sociais, de outro. Não se trata, nesse sentido, de "uso" da cultura pop pela religião ou da "veiculação" da religião via entretenimento, mas, a julgar pelos nomes e autodescrições, uma forma midiatizada de vivência do religioso, sem possibilidade de redução a qualquer um de seus termos originários.

\section{A FLUTUAÇÃO DE SENTIDOS ENTRE POP E RELIGIÃO}

No painel rotativo da página inicial do portal O Cristão Geek (2020), aparece uma imagem com o personagem Batman lutando contra o Super-Homem, referência ao filme “Batman vs. Superman”, lançado em 2016. Na parte esquerda, no entanto, a referência 
não é ao enredo, mas a um versículo da Bíblia (Mateus, 12:25): "Toda casa dividida contra si mesma não subsistirá". O sentido da disputa entre as personagens é revestido de outra dimensão, tratado como exemplo ou ilustração do que está sendo dito na passagem bíblica. Ao mesmo tempo, a colocação desse trecho ao lado de figuras do entretenimento produz um deslocamento em relação à expectativa original da citação no contexto religioso.

Como indica Fausto Neto (2004), "estas novas formas de organizar palavras para dar origens a novos vínculos entre instituições e fiéis estão atravessadas por gramáticas que instituem os 'contratos de leitura' e, consequentemente, novos sentidos às práticas religiosas" (p. 22). Há uma flutuação entre os sentidos laicos e religiosos, em um transbordamento de fronteiras que se dirige para uma compreensão doutrinária das produções da mídia. Não se trata, no entanto, apenas de "exemplificar" o trecho bíblico com uma ilustração; trata-se de acionar um conjunto de referências e sentidos no âmbito da cultura pop sem os quais a compreensão da mensagem tende a ficar comprometida: é preciso saber não apenas que Batman e Super-Homem estão do mesmo lado, mas também conhecer o filme de 2016. Ao mesmo tempo, o versículo de $\mathrm{S}$. Mateus dirige esse conhecimento para o universo religioso.

Nos portais analisados, a cultura pop e o entretenimento aparecem dentro de um enquadramento denominacional e religioso, com as discussões sendo pautadas por essa temática: não se trata, em geral, de discutir a cultura pop em si, mas dentro de um referencial de crenças e valores definidos - no caso, pelo vínculo com uma religião.

De maneira semelhante, na página inicial da Loja KOK (2020), há um anúncio de uma camiseta na qual está escrita "Birds of Pray", título original do filme "Aves de Rapina", lançado em 2020. Ao lado, uma imagem mostrando a protagonista, Arlequina, cercada de outras personagens em tamanho menor. 0 nome do filme, mostrado em letras maiúsculas na fonte usada pela produtora, é acompanhado das palavras "As garotas das orações fantabulosas" e, novamente, de uma referência à Bíblia (Mateus, 7:11), sem o trecho em si.

Assim como no exemplo anterior, nota-se o trânsito de sentidos entre o entretenimento e a esfera religiosa, sem uma solução de ruptura ou continuidade, no laço entre os dois universos. Neste caso, é possível observar a atualidade do tema: a camiseta à venda faz referência ao filme estreado em fevereiro de 2020 no Brasil. 
O ponto de intersecção na camiseta é baseado no título original do filme, "Aves de Rapina: Arlequina e sua emancipação fantabulosa” ("Birds of Prey: And the Fantabulous Emancipation of One Harley Quinn”, em inglês), modificado posteriormente, por razões comerciais, para "Arlequina em: Aves de Rapina”. É interessante notar o uso, na camiseta, da palavra "fantabulosa", tradução, quase uma transliteração, do original inglês “fantabulous" - a palavra não existe na língua portuguesa. Na camiseta da Loja KOK, o adjetivo é atribuído às orações das garotas: a clivagem de gênero, presente na temática do filme, é mantida no anúncio.

Como recorda Meyer (2012), “a adoção de novas mídias não acontece em um vácuo, mas está ligada a processos sociais e culturais mais amplos” (p. 164). O destaque, portanto, não se refere à técnica ou tecnologia, como o uso de vídeos ou podcasts, mas às relações entre campos da experiência humana distantes, como pontua McDannell (2012) na perspectiva clássica da religião como forma de atribuir a característica de "sagrado" ou “profano" às práticas simbólicas.

Articulações semelhantes podem ser encontrados na parte de vendas do site 0 Cristão Geek. Em uma das camisetas, uma imagem do Capitão América no filme Guerra Civil, de 2016, é secundada pelas palavras "Civil War - I want you” e, logo abaixo, “\#teamJesus" (“Guerra Civil - Eu quero você - \#timeJesus". O agrupamento de referências é representativo da estratégia de intersecção entre cultura pop e religião, acrescido de outros elementos da cultura do ambiente da mídia, como o uso do sinal "\#” para indicar um marcador e da expressão "time”, usada eventualmente em reality shows para identificar a equipe dos participantes.

Os exemplos poderiam se multiplicar, à medida que há referências a diversas personagens, séries e franquias presentes no universo do entretenimento e da cultura pop. Como argumenta Clark (2007):

Religião é muito mais do que aquilo que acontece durante os cultos ou orações, e muito mais do que um conjunto de crenças ou compromissos ideológicos. Religião é vivida na vida cotidiana e, dessa maneira, há objetos e práticas que se tornam parte das práticas religiosas, seja de maneira formal ou informal (p. 5).

Em um texto anterior, Clark (2002) já indicava essa demanda de inserção da religião no contexto de um público progressivamente ambientado nas práticas da mídia. A cultura material, em sua ambivalente relação com o mercado e o consumo, é parte da vivência religiosa. 
Essas práticas são colocadas dentro de um enquadramento religioso, seja pela referência a algum trecho da Bíblia ou a rituais: uma camiseta da Loja Nerd Cristão (2020) estampa o logotipo do Batman, mas com a palavra "Batizado", fazendo uso do prefixo "bat" como nas histórias do herói. O substrato comum é o componente de novidade gerado pelos deslocamentos de contexto, tanto da cultura pop, quanto da religião. Esse duplo afastamento dos espaços originais de produção gera um sentido que, sem deixar de lado vinculações iniciais, apresenta-se como novo a partir da intersecção dos anteriores.

Nos casos analisados, os acionamentos do entretenimento são direcionados para o enquadramento religioso, razão de ser e a finalidade de existência desses portais. Emerge, a partir daí, um sentido novo para a prática cultural laica representada pelo entretenimento, colocado dentro de uma perspectiva que permite não apenas sua leitura, mas sobretudo sua interpretação no âmbito da religião.

\section{A INTERPRETAÇÃO RELIGIOSA DA CULTURA POP}

No entanto, essa não é a única exposição dos discursos da cultura pop nos portais analisados. De um lado, essa cultura material parece ser um aspecto particularmente relevante nesses sites, sobretudo quando se recorda, com Featherstone (1995) ou Jenkins (2006), que a lógica do entretenimento está diretamente ligada à perspectiva do consumo cultural. De outro, é preciso observar que a presença da cultura pop é, em alguns momentos, um pretexto para a discussão dos temas nela apresentados, mas a partir de um viés religioso.

As estratégias de acionamento da cultura pop como ponto de partida para a discussão de temas religiosos, em geral dentro de uma perspectiva ética ou moral, podem ser vistas sobretudo nos portais Parábolas Geek e Bando de Quadrados. Se a perspectiva anterior era pautada na relação imediata entre imagens e frases conhecidas, aqui o ponto é o desenvolvimento de temáticas específicas tendo como pretexto os produtos do entretenimento. As postagens, neste caso, desenvolvem pontos mais próximos de questões cotidianas: há, aparentemente, um uso ostensivo do que Morin (1989) denomina a "lógica do olimpiano" em termos de promover um jogo constante de aproximação e distância entre o conteúdo dos produtos da mídia e problemas do cotidiano, interpretados dentro de uma perspectiva religiosa e doutrinária. 
No portal Bando de Quadrados, no canal "Palavra Nérdica”, uma postagem dezembro 2019 discute as posturas diante da morte a partir do filme Star Wars: a Ascensão Skywalker, estreado cerca de dez dias antes. Um dos pontos principais do enredo é o reaparecimento do imperador Palpatine, dado como morto em $O$ retorno de Jedi, de 1983. No universo da franquia, usando seu conhecimento do lado sombrio da Força, Palpatine mantém-se artificialmente vivo, fora de qualquer perspectiva natural. 0 autor da postagem utiliza essa atitude para discutir a postura do fiel diante da morte e menciona, como maneira adequada, aquela adotada pelos heróis da saga, os Jedis:

De modo bastante diferente temos os Jedi que aceitam a morte como sendo um 'unir-se com a força'. Aceitando de bom grado o fato de que sua missão se cumpriu e agora é preciso viver em outro plano (...). Assim como para os Jedi, a morte em Cristo nada mais é do que um 'unir-se ao nosso Mestre' e isso acontece de forma plena, pois um dia o veremos face a face e cada dia mais a nossa esperança se reacende em viver uma vida plena naquele que é o nosso criador (CAMPOS, 2019).

O domínio de referências de dois universos distintos, o religioso e o entretenimento, apresenta-se como ponto fundamental para a produção de sentidos nesta postagem. O emprego de referências da Bíblia em vários pontos do texto parece ser o recurso discursivo para a inserção das concepções religiosas como forma de interpretação da cultura pop. Nesse sentido, Bronsztein e Covaleski (2012) indicam que na "multiplicidade de formas e expressões novas, o anúncio religioso se dearticula nos moldes da contemporaneidade e dialoga com anseios humanos de entretenimento, participação e engajamento" (p. 96).

No portal Parábola Geek, também se observa uma tentativa de aproximação entre a mensagem doutrinária e o ambiente da mídia conhecido por seu público, para quem a cultura pop não é apenas um produto de consumo imediato ou uma preferência, mas um conjunto de referenciais presentes em seu cotidiano. A preocupação com a atualidade do texto é presente aqui também: a título de ilustração, uma coluna do autor (MEDEIROS, 2019), postada em julho de 2019 e intitulada “Estamos todos longe de casa" utiliza como gancho o filme Homem-Aranha: longe de casa, então recém-estreado. Algumas das temáticas levantadas pelo filme são entrelaçadas com proposições religiosas:

Não importa se você tem a capacidade de viajar pelas estrelas com o poder da Capitã Marvel, ou se é o Rei de Asgard como Thor, ou se é o amigo da vizinhança, como o Homem-Aranha o que realmente conta é que tudo o que fizermos na terra terá um grande impacto na Eternidade e na vida de pessoas (MEDEIROS, 2019). 
No trecho, há alusões aos poderes de várias heroínas e heróis, sem maior detalhamento, sugerindo que o público leitor não apenas tem essas informações, mas também pode lidar com elas rapidamente no sentido indicado pela leitura. Os comentários ao filme são acompanhados de citações da Bíblia.

Para Fausto Neto (2006), "essas estratégias estariam também a serviço de demandas dos sujeitos, realizando, segundo peculiares pedagogias midiáticas e discursivas, não apenas um novo modo de 'gestão da crença'”, mas, continua, “também processos de atendimentos das demandas relacionadas a dimensões situacionais da vida dos fiéis" (p. 12).

As relações entre aspectos doutrinários e cultura pop, no ambiente de midiatização da religião, não deixa de ser problematizado pelos próprios portais em momentos pontuais. Em uma postagem de 8 de fevereiro de 2020 do canal "Palavra Nérdica" do portal Bando de Quadrados, o autor menciona sua preocupação com a delimitação de espaços e influências entre os dois universos de sentido, concluindo por sua intersecção como maneira de vivenciar o religioso ao mesmo tempo em que não deixa de lado suas preferências e práticas culturais. 0 autor toma como ponto de partida da música In the End, da banda norte-americana Linkin Park:

Esse é um trecho de uma música dita não cristã, mas Deus pode usar até uma mula para falar não é mesmo? Eu estava ouvindo a música In The End, de Linkin Park, quando parei e ouvi muito essa parte da música. Quando eu parei para perceber, eu tinha sido ministrado através de uma música "mundana", tive alguns momentos de dúvida, de pensamentos meus brigando comigo mesmo, porém, quando não é uma ministração de nós mesmo, o medo vai embora, as dúvidas vão embora e nós temos a real certeza que veio de Deus (CAMPOS, 2020).

Seria possível prosseguir com exemplos desse tipo de interpretação que procura realizar uma leitura religiosa de produtos da cultura pop, não no sentido eventual de uma crítica à qualidade, mas agregando-os como parte das vivências de um público mergulhado nesse universo.

Espera-se, do mesmo modo, familiaridade de leitoras e leitores com os temas doutrinários, bem como as práticas esperadas das pessoas vinculadas a uma religião. Como recorda Viviane Borelli (2009), "os dispositivos midiáticos representam uma ampliação do contato entre religião e fiéis, formando novas comunidades de pertencimento, e prossegue afirmando que "a midiatização, seus processos e lógicas de funcionamento perpassam não só o campo religioso, mas também o âmbito da recepção" (p. 13). 
Nota-se, finalmente, a ausência de elementos denominacionais ou ligados exclusivamente a uma igreja específica. Há, no conjunto dos textos, a prevalência do que poderia ser interpretado como um ethos evangélico a partir do qual os produtos midiáticos são lidos e interpretados, mas com raras menções a este ou aquele grupo religioso.

\section{CONSIDERAÇÕES FINAIS}

Por fim entendi que não precisava deixar de ser Nerd pra ser Shalom nem muito menos para ser cristão. Eu só precisava formar a minha imaginação para filtrar aquilo que me convém como filho amado de Deus. E fica a dica: sendo Nerd ou não, em tudo o que você assiste, lê ou ouve, procure entender se aquilo the fará crescer e se não o levará ao pecado. E é claro, se realmente é uma boa história ou não, por que somos filhos de Deus e ninguém merece um filme ruim, né (VINICIUS, 2016)?

Este trecho de um artigo intitulado "Ser cristão e nerd é possível?", do portal da comunidade católica ComShalom, não está compreendido no "corpus" deste artigo, mas, por seu caráter de síntese, pode ser citado a título de ilustração. "Ser nerd e cristão" é possível, em uma relação que presume, da parte do fiel, os critérios para posicionar aspectos religiosos e doutrinários diante de sua condição de fã: a reivindicação do vínculo religioso parece ter precedência em relação a qualquer outro - como talvez seja de se esperar levando-se em consideração que a origem da mensagem são portais religiosos. Marchessault (2011), trabalhando as articulações entre religião e entretenimento, indica como condição de "compatibilidade" entre ambos não apenas o que seria um "uso" instrumental da mídia, ou das formas do entretenimento, como canal, mas uma articulação mais detalhada em termos de forma e conteúdo.

Historicamente, o processo de midiatização da religião vem sendo marcado pela articulação progressiva com os diversos ambientes da mídia, dos jornais e do rádio, até a explosão das práticas neopentecostais na televisão. Apesar disso, os anos recentes vêm observando a ramificação do fenômeno em websites, redes sociais, aplicativos e até mesmo memes de internet. Retomando uma divisão proposta em outro momento - cf. Martino (2016a) - é possível observar um predomínio cada vez maior não apenas de denominações altamente vinculadas à mídia, assim como o surgimento de maneiras de vivenciar as experiências religiosas que, dentro desse ambiente midiático, não precisam mais, necessariamente, de um vínculo institucional fechado. 
Dentro dos processos de midiatização da religião, este tipo de procedimento se apresenta com características múltiplas, nas quais os aspectos doutrinários e midiáticos se entrelaçam a ponto de se tornarem irredutíveis um ao outro, embora, no aspecto tensional relacionado com esse tipo de articulação, observa-se a prevalência do discurso religioso - não é possível perder de vista a origem institucional dos portais, voltada para a divulgação de uma religião.

\section{REFERÊNCIAS}

AMARAL, Adriana. Cultura pop digital brasileira. Eco-Pós, Rio de Janeiro, v. 19, n. 3, p. 68-89, 2016.

BANDO DE QUADRADOS. Bando de quadrados: o mundo nerd sem limites, c2021. Página inicial. Disponível em: https://bit.ly/2S8xSQe. Acesso em: 29 fev. 2020.

BICCA, Angela Dillmann Nunes. et al. Identidades nerd/geek na web: um estudo sobre pedagogias culturais e culturas. Conjectura, Caxias do Sul, v. 18, n. 1, p. 87-104, 2013.

BORELLI, Viviane. Comunidade de recepção e os sentidos do religioso e do midiático. In: ENCONTRO DA COMPÓS, 19., 2010, Rio de Janeiro. Anais [...]. Rio de Janeiro: PUC-RJ, 2010.

BOURDIEU, Pierre. A distinção. São Paulo: Zouk, 2011.

BRABAZON, Tara. From revolution to revelation. Londres: Ashgate, 2008.

BRONSZTEIN, Karla Regina Macena Patriota; COVALESKI, Rogério Luiz. Religious branded content: entretenimento, mídia e marca nas ações publicitárias da Igreja Universal do Reino de Deus. Rever, São Paulo, v. 12, n. 2, p. 81-99, 2012.

BUDDENBAUM, Judith Mitchell. Social Science and the study of media and religion: going forward by looking backward. Journal of Media and Religion, Abingdon-on-Thames, v. 1, n. 1, p. 13-24, 2002.

CAMPOS, Tato. Star Wars: os Sith e o constante medo da morte. Bando de Quadrados, [S.I.], 26 dez. 2019. Disponível em: https://bit.ly/3wWQSjH. Acesso em: 29 fev. 2020.

CAMPOS, Tato. E no final, o que realmente importa? Bando de Quadrados, [S.I.], 8 fev. 2020. Disponível em: https://bit.ly/3wTosqM. Acesso em: 29 fev. 2020.

CLARK, Lynn Schofield. Overview: the "protestantization" of research into media, religion, and culture. In: HOOVER, Stewart; CLARK, Lynn Schofield (org.). Practicing religion in the media age. New York: Columbia University Press, 2001.

CLARK, Lynn Schofield. U. S. Adolescent religious identify, the media, and the 'funky' side of religion. Journal of Communication, Oxford, v. 52, n. 4, p. 794-811, 2002. 
CLARK, Lynn Schofield. Introduction: identity, belonging, and religious lifestyle branding. In: CLARK, Lynn Schofield. Religion, the media, and the marketplace. New Brunswick: Rutger University Press, 2007.

COSGEL, Metin; MINKLER, Lanse. Religious Identity and Consumption. Review of Social Economy, Abingdon-on-Thames, v. 62, n. 3, p. 339-350. 2004.

CUNHA, Magali do Nascimento. O lugar das mídias no processo de construção imaginária do "inimigo" no caso Marco Feliciano. Comunicação, Mídia e Consumo, São Paulo, v. 10, p. 51-74, 2013.

DYER, Richard. Only Entertainment. Londres: Routledge, 1998.

FAUSTO NETO, Antonio. A igreja doméstica: estratégias televisivas de construção de novas religiosidades. São Leopoldo: Unisinos, 2004.

FAUSTO NETO, Antonio. Dispositivos de telecura e contratos da salvação. Comunicação, Mídia e Consumo, São Paulo, v. 3, n. 6, p. 11-36, 2006.

FEATHERSTONE, Mike. Cultura de consumo e pós-modernismo. São Paulo: Studio Nobel, 1995.

FEITOZA, Mirna; SANTAELLA, Lucia (org.). O mapa do jogo. São Paulo: Cengage, 2008.

FIEGENBAUM, Ricardo Z. Midiatização do campo religioso: tensões e peculiaridades de uma relação de campos. UNIrevista, São Paulo ,v. 1, n. 3, p. 1-12, jul. 2006.

FISKE, John. Understanding popular culture. Londres: Routledge, 1998.

GOMES, Pedro Gilberto. Processos midiáticos e construção de novas religiosidades: dimensões históricas. São Leopoldo: Unisinos, 2004.

HJARVARD, Stig. The mediatization of religion. Northern Lights, Bristol, v. 6, n. 1, p. 9-26, 2008.

JENKINS, Henry. Convergence Culture. Nova York: NYU, 2006

LOJA KOK. Loja online de Loja KOK, C2021. Página inicial. Disponível em: https://bit.ly/2S4pGRc. Aceso em: 29 fev. 2020.

LYUTEN, Sonia. Mangá. São Paulo: Hedra, 2008.

MARCHESSAULT, Guy. Religion et entertainment sont-ils compatibles? Global Media Journal Édition Canadienne, v. 4, n. 1, p. 61-76, 2011.

MARIANO, Ricardo. Neopentecostais. São Paulo: Loyola, 1999.

MARTINO, Luis Mauro Sa. The mediatization of religion. Londres: Routledge, $2016 a$.

MARTINO, Luis Mauro Sa. Mídia, religião e sociedade. São Paulo: Paulus, $2016 \mathrm{~b}$. 
MARTINO, Luís M. S. Rumo a uma teoria da miditização: exercício conceitual e metodológico. InTexto, Porto Alegre, v. 1, n. 45, p. 16-34, 2019.

MATOS, Patrícia. O nerd virou cool: identidade, consumo midiático e capital simbólico em uma cultura juvenil em ascensão. In: CONGRESSO DE CIÊNCIAS DA COMUNICAÇÃO NA REGIÃO SUDESTE, 16., 2011, São Paulo. Anais [...]. São Paulo: Sociedade Brasileira de Estudos Interdisciplinares da Comunicação, 2011. MATOS, Patrícia. Da vergonha ao orgulho: consumo, capital simbólico e ressignificação midiática da cultura nerd. In: CONGRESSO DE CIÊNCIAS DA COMUNICAÇÃO, 35., 2012, Fortaleza. Anais [...]. São Paulo: Sociedade Brasileira de Estudos Interdisciplinares da Comunicação, 2012.

MCDANNELL, Colleen. Scrambling the sacred and the profane. In: LYNCH, Gordon; MITCHELL, Jolyon; STRHAN, Anna. Religion, Media and Culture: a reader. Londres: Routledge, 2012. p. 135-146.

MCROBBIE, Angela. Postmodernity and popular culture. Londres: Routledge, 2003.

MEDEIROS, Eduardo. Estamos todos longe de casa. Parábolas Geek, [S.I.], 4 jul. 2019. Disponível em: https://bit.ly/3uKX24W. Acesso em: 29 fev. 2020.

MEYER, Birgit. Religious sensations: media, aesthetics and the study of contemporary religion. In: LYNCH, Gordon; MITCHELL, Jolyon; STRHAN, Anna. Religion, media and culture: a reader. Londres: Routledge, 2012. p. 159-170.

MIKLOS, Jorge. Ciber-religião: a construção de vínculos religiosos na cibercultura. Aparecida: Ideias e Letras, 2012.

MORIN, Edgar. Cultura de massas no século XX. Rio de Janeiro: Forense, 1989.

NERD CRISTÃO. O nerd cristão, c2021. Página inicial. Disponível em: https://bit.ly/3g2Q9GS. Acesso em: 29 fev. 2020.

O CRISTÃO GEEK. O cristão geek, c2021. Página inicial. Disponível em: https:/ /bit.ly/3wMroVS. Acesos em: 29 fev. 2020.

PARABOLAS GEEK. Parábolas geek: cultura pop cristã, c2021. Página inicial. Disponível em: https://bit. ly/3wURWnU. Acesso em: 29 fev. 2020.

PANKE, Luciana. Política e entretenimento: cruzamento e/ou interferência na construção de sentidos. Animus, Vol. 18, no. 1, pp. 13-30, 2010.

RAMOS, Hudson; PATRIOTA, Karla. Experiências religiosas de comunidade no ciberespaço. Ícone, Recife, v. 16, n. 1, p. 120-132, 2018.

ROMANOWSKI, W. Pop culture wars. London: Verso, 2006. 
SANTOS, Suzane de Souza et al. O nerd no centro do mercado midiático. In: CONGRESSO DE CIÊNCIAS DA COMUNICAÇÃO NA REGIÃO SUDESTE, 20., 2015, Uberlândia. Anais [...]. São Paulo: Sociedade Brasileira de Estudos Interdisciplinares da Comunicação, 2015.

SOARES, Thiago. Abordagens teóricas para o estudo da cultura pop. Logos, Rio de Janeiro, v. 2, n. 24, p. 1-15, 2014.

SOUZA, Marco. As encenações do 'televangelismo' como forma de entretenimento. Logos, Rio de Janeiro, v. 11, n. 21, p. 89-105, 2004.

SOUZA, André Ricardo de. Igreja in concert. São Paulo: Annablume, 2005.

STOUT, Daniel; BUDDENBAUM, Judith. Genealogy of an Emerging Field: Foundations for the Study of Media and Religion. Journal of Media and Religion, Abington-on-Thames, v. 1, n. 1, p. 5-12, 2002.

STOUT, Daniel; BUDDENBAUM, Judith. Approaches to the study of media and religion. Religion, Amsterdam, v. 38, n. 1, p. 226-232, 2008.

STREET, John. Rebel rock. Londres: Blackwell, 1986.

STREET, John. Mass media, politics and democracy. Londres: Palgrave, 2001.

TRIGO, Luiz Gonzaga Godoi. Entretenimento. São Paulo: Senac, 2003.

VAN ZOONEN, Liesbet. Entertaining the citizen. Londres: Rowman \& Littlefield, 2005.

VINICIUS, André. Ser cristão e nerd é possível? ComShalom, [S.I.], 10 nov. 2016. Disponível em: https:// bit.ly/3uHnV9L. Acesso em: 29 fev. 2020.

WEBER, Max. Economia e Sociedade. Vol. 1. Brasília: Ed. UnB, 1991.

\section{NOTA}

10 autor agradece aos escritores Thiago Lee e AJ Oliveira pela ideia na origem deste texto, bem como aos pareceristas pelas sugestões de aprimoramento.

Artigo recebido em: 8 de março de 2020.

Artigo aceito em: 23 de maio de 2021. 